\title{
INCLUSÃO ESCOLAR DE PESSOAS COM DEFICIÊNCIA E A PERSPECTIVA DA FAMÍlIA: ANÁLISE DA PRODUÇÃO ACADÊMICA DE 2009 A 2019
}

\author{
SCHOOL INCLUSION OF PEOPLE WITH DISABILITIES AND THE FAMILIES' \\ PERSPECTIVE: ANALYSIS OF ACADEMIC PRODUCTION FROM 2009 TO 2019
}

\author{
iD Flávia Laryssa Gonzaga Rabelo \\ Pedagoga \\ Universidade Federal do Rio Grande do Norte - UFRN \\ Natal, Rio Grande do Norte - Brasil. \\ laryssarabello@gmail.com
}

\author{
Rita de Cássia Barbosa Paiva Magalhães \\ Doutora em Educação \\ Universidade Federal do Rio Grande do Norte - UFRN \\ Natal, Rio Grande do Norte - Brasil. \\ ritam.ppgedufrn@gmail.com
}

\begin{abstract}
Resumo: Este trabalho tem como objetivo analisar as produções acadêmicas produzidas no período de 2009 a 2019 sobre a inclusão escolar da pessoa com deficiência, levando em consideração a perspectiva da família. Para isso, realizou-se um levantamento das produções de teses e dissertações no Catálogo de Teses e Dissertações da Capes e na Biblioteca Digital Brasileira de Teses e Dissertações. Com base em Maturana e Cia (2015) e Bardin (2011), construiuse uma ficha de análise das produções levantadas. Destaca-se que a maioria das pesquisas apresentaram como pressuposto o modelo social da deficiência, o que mostra um grande avanço conquistado pelas políticas de educação especial. Conclui-se que analisar as produções acadêmicas sobre a inclusão escolar de pessoas com deficiência que consideravam a perspectiva das famílias trouxe contribuições para entender como a temática vem sendo estudada e para criar um panorama desses estudos.
\end{abstract}

Palavras-chave: educação especial; família; escola.

Abstract: This paper aims to analyze the academic production about the school inclusion of people with disabilities considering the family's perspective that were produced in the period from 2009 to 2019. For this, it was reviewed the production of theses and dissertations in the Catálogo de Teses e Dissertações da Capes and Biblioteca Digital Brasileira de Teses e Dissertações. Based on Maturana \& Cia (2015) and Bardin (2011) we built an analysis sheet of the researches raised. We point out that the most of research works presented the social model of disability as an assumption, which shows us a great advance achieved by the special education policies. We consider that analyzing the academic productions on the school inclusion of people with disabilities who considered the family's perspective brought contributions to understand how the theme has been studied and create an overview of these studies.

Keywords: special education; family; school.

Para citar - ABNT NBR 6023:2018

RABELO, Flávia Laryssa Gonzaga; MAGALHÃES, Rita de Cássia Barbosa Paiva. Inclusão escolar de pessoas com deficiência e a perspectiva da família: análise da produção acadêmica de 2009 a 2019. Cadernos de Pós-graduação, São Paulo, v. 20, n. 1, p. 145162, jan./jun. 2021. Disponível em: https://doi.org/10.5585/cpg.v20n1.19788. 


\section{Introdução}

A pessoa com deficiência, historicamente, vem sendo excluída da sociedade e do ambiente escolar. No Brasil, no período anterior às décadas de 1960 e 1970, predominou uma vertente médico-patológica da deficiência, que os considerou como doentes, incapazes e que precisavam ser curados (GODOY, 2002). A educação, nesse período, desenvolvia-se em regime domiciliar ou institucional. Sassaki (2006, p. 29) afirma que essa concepção de deficiência até hoje é "responsável, em parte, pela resistência da sociedade em aceitar a necessidade de mudar suas estruturas e atitudes para incluir em seu seio as pessoas com deficiência".

A partir da década de 1960 houve um boom de instituições especializadas, escolas especiais, centros de habilitação e reabilitação, um período conhecido como integração, que buscou inserir as pessoas com deficiência nos ambientes sociais e educacionais. Contudo, por fim, a integração foi um esforço apenas unilateral da pessoa com deficiência, da família, instituições especializadas e alguns poucos simpatizantes da causa (SASSAKI, 2006).

As décadas de 1980 e 1990 foram fundamentais para mais uma mudança de compreensão sobre a pessoa com deficiência e os seus direitos. Esse período foi marcado por documentos, ações e leis que consagraram a inclusão como o modelo a ser buscado dali em diante, com o objetivo de garantir à pessoa com deficiência uma educação inclusiva.

Documentos como a Constituição Federal (BRASIL, 1988); a Convenção sobre os Direitos da Criança (UNICEF, 1989); a Lei nº 7.853/89 (BRASIL, 1989); a Declaração de Educação para Todos (UNICEF, 1990); a Declaração de Salamanca (UNESCO, 1994) e a Lei de Diretrizes e Bases da Educação Nacional (BRASIL, 1996) foram marcos fundamentais para a garantia dos direitos das pessoas com deficiência, principalmente no que concerne à educação. Assim, esses marcos serviram como pilares para a construção das próximas políticas públicas, práticas educacionais e pesquisas no campo da Educação Especial.

Algo importante a se destacar é que o paradigma da inclusão, como afirma Sassaki (2006, p. 21) "consiste em adequar os sistemas sociais gerais da sociedade de tal modo que sejam eliminados os fatores que excluíam certas pessoas do seu seio e mantinham afastadas aquelas que foram excluídas". Assim, esse paradigma não tem mais como concepção o modelo médico-patológico de deficiência, ao qual a pessoa com deficiência que precisava se adequar. Corroborando com essa concepção, no documento da Convenção sobre os Direitos das Pessoas com Deficiência (BRASIL, 2007, p. 16), promulgado pelo Brasil pelo Decreto n 6.949/09, a pessoa com deficiência é reconhecida como: “[...] aquelas que têm impedimentos de longo prazo de natureza física, mental, intelectual ou sensorial, os quais, em interação com diversas barreiras, podem obstruir sua participação plena e efetiva na sociedade em igualdades de condições com as demais pessoas" (grifo nosso). 
Ao promulgar a convenção, o Brasil passa a adotar nas próximas políticas essa concepção de deficiência, a qual leva em consideração também a interação da pessoa com o meio no qual ela está inserida. Corroborando com essa concepção, Diniz, Barbosa e Santos (2009, p. 66) afirmam que a "deficiência não é apenas o que o olhar médico descreve, mas principalmente a restrição à participação plena provocada pelas barreiras sociais". A partir da Convenção sobre os Direitos das Pessoas com Deficiência (BRASIL, 2007), essa concepção de deficiência conhecida como Modelo Social da Deficiência se tornou mais presente nos trabalhos científicos produzidos e na elaboração das políticas públicas voltadas às pessoas com deficiência.

Ainda na Política Nacional de Educação Especial na Perspectiva da Educação Inclusiva (2008), a educação inclusiva é colocada como central no debate para a construção de uma sociedade que supere a lógica da exclusão, confrontando práticas discriminatórias e criando alternativas para superá-las. Com o mesmo objetivo, no preâmbulo do texto da Convenção sobre os Direitos das Pessoas com Deficiência (BRASIL, 2007, p. 16), a família é apresentada como o "o núcleo natural e fundamental da sociedade", a qual tem:

o direito de receber a proteção da sociedade e do Estado e de que as pessoas com deficiência e seus familiares devem receber a proteção e a assistência necessárias para tornar as famílias capazes de contribuir para o exercício pleno e eqüitativo dos direitos das pessoas com deficiência.

Sabe-se que, desde quando se iniciou o processo de luta pelos direitos das pessoas com deficiência e se começou a buscar formas de integrar ou incluir a pessoa com deficiência na escola e na sociedade, a família teve um papel primordial. Como afirma Smith (2008), os esforços de pais, mães, profissionais da educação e da própria pessoa com deficiência foram fundamentais para a conquista de direitos e mudanças na melhoria de oportunidades disponíveis para todos os indivíduos.

A Lei brasileira de Inclusão da Pessoa com Deficiência (BRASIL, 2015) afirma que cabe ao Estado, à sociedade e à família o dever de assegurar os direitos da pessoa com deficiência, inclusive àqueles relativos à inclusão escolar, assegurando uma educação de qualidade. Assim, a inclusão é um esforço que a sociedade como um todo deve empreender para acolher e atender às necessidades de todas as pessoas.

Polonia e Dessen (2005), Dessen e Polonia (2007) e Maturana e Cia (2015) mostram, por exemplo, a importância da relação entre a escola e a família para o desenvolvimento e a aprendizagem humana. Essas autoras também relatam sobre a relevância de estudos nessa área para identificar as condições de comunicação e colaboração entre essas duas instituições, já que o sucesso nessa relação é um fator facilitador da inclusão escolar. 
Sabendo da importância da família para a construção de uma educação mais inclusiva, questionou-se como ela tem aparecido nas pesquisas científicas da área. Para tal, tornou-se necessário investigar sobre como os estudos, que levam em consideração a perspectiva das famílias sobre a inclusão, têm abordado a temática, quais os familiares investigados e como essas famílias e pessoas com deficiência têm construído as suas trajetórias escolares.

No sentido de encontrar respostas a esses questionamentos, teve-se como objetivo analisar as produções acadêmicas produzidas sobre a inclusão escolar da pessoa com deficiência que levam em consideração a perspectiva da família no período de 2009 a 2019. Considerou-se esse recorte temporal para contemplar as discussões que surgiram após o Brasil promulgar a Convenção sobre os Direitos das Pessoas com Deficiência, pela sua importância em consolidar o modelo social da deficiência nas políticas nacionais de educação especial.

O estudo delineia-se como bibliográfico, pois este permite a investigação de uma gama de fenômenos muito mais ampla e de dados dispersos pelo espaço e tempo, aos quais não seria possível acessar em uma pesquisa direta (GIL, 2008). O levantamento bibliográfico seguiu as seguintes etapas: escolha das bases de dados a serem pesquisadas e dos descritores utilizados; leitura de títulos e resumos de todos os trabalhos encontrados; leitura integral das produções selecionadas; catalogação e construção da ficha de análise e análise das produções.

Com base na ficha de registro produzida por Maturana e Cia (2015), que analisaram a produção de teses e dissertações sobre a relação família-escola de crianças público-alvo da educação especial no período de 2001 a 2011 e na análise de conteúdo de Bardin (2011), construiu-se uma ficha de registro de categorias para que as teses e as dissertações fossem analisadas.

A ficha construída, assim como a de Maturana e Cia (2015), dividia-se em duas partes. Na identificação do material continha o tipo de produção (tese ou dissertação); autor e ano de produção; instituições e programas de pós-graduação. Na segunda parte, a que condizia com a análise do texto e conteúdo, continha tema principal da pesquisa; sujeitos participantes da pesquisa; públicoalvo da pesquisa; metodologia e modelo de deficiência abordado pelo trabalho. As categorias levantadas foram utilizadas para organizar a análise e a discussão deste artigo.

\section{Análise e Discussão}

Considerou-se neste trabalho as teses e as dissertações encontradas nas seguintes bases de dados: Catálogo de Teses e Dissertações da Capes; Biblioteca Digital Brasileira de Teses e Dissertações. Para a pesquisa, utilizou-se os seguintes descritores e operadores booleanos: "deficiência" AND “inclusão escolar” OR “escolarização” OR “escola” AND “família” OR “mães” OR "pais”. 
Em uma busca inicial, o Catálogo de Teses e Dissertações da Capes mostrou 11 trabalhos, dentre eles, 4 encontrados eram anteriores à Plataforma Sucupira e não estavam disponíveis e outros 4 não tinham divulgação autorizada. Porém, pelo contato com os autores, conseguiu-se que um deles enviasse o trabalho de dissertação de forma integral. Concluiu-se que os 3 trabalhos restantes junto ao que foi enviado depois da solicitação, após a leitura de título e resumos correspondiam ao objetivo da pesquisa, ou seja, abordavam o tema da inclusão escolar de pessoas com deficiência e continham a perspectiva da família.

A Biblioteca Digital Brasileira de Teses e Dissertações (BDTD) mostrou, na busca inicial, 193 resultados, levando em consideração os trabalhos que continham algum dos descritores no título. Após a leitura de títulos e resumos, selecionaram-se 13 trabalhos e, após a eliminação de uma replicação, totalizaram-se 12 trabalhos selecionados nesta base de dados.

Apesar da BDTD apontar mais resultados, o Catálogo de Teses e Dissertações da Capes foi mais preciso em relação aos descritores utilizados. Assim, selecionou-se, no total, 16 trabalhos de teses e dissertações para esta análise, 4 (25\%) do Catálogo de Teses e Dissertações da Capes e $12(75 \%)$ da BDTD.

O maior número de trabalhos encontrados foi de dissertações de mestrado, totalizando 12 (75\%), enquanto encontrou-se apenas $4(25 \%)$ teses de doutorado. Sobre a produção de teses e dissertações por ano, os anos mais produtivos foram 2014 e 2017, com $3(18,8 \%)$ trabalhos cada, 4 dissertações e 2 teses, enquanto nos anos de 2012 e 2013 foram encontradas 2 (12,5\%) dissertações em cada. Nos anos restantes encontrou-se apenas 1 (6,3\%) trabalho em cada, distribuídos entre teses e dissertações.

Figura 1 - Produções de teses e dissertações por região

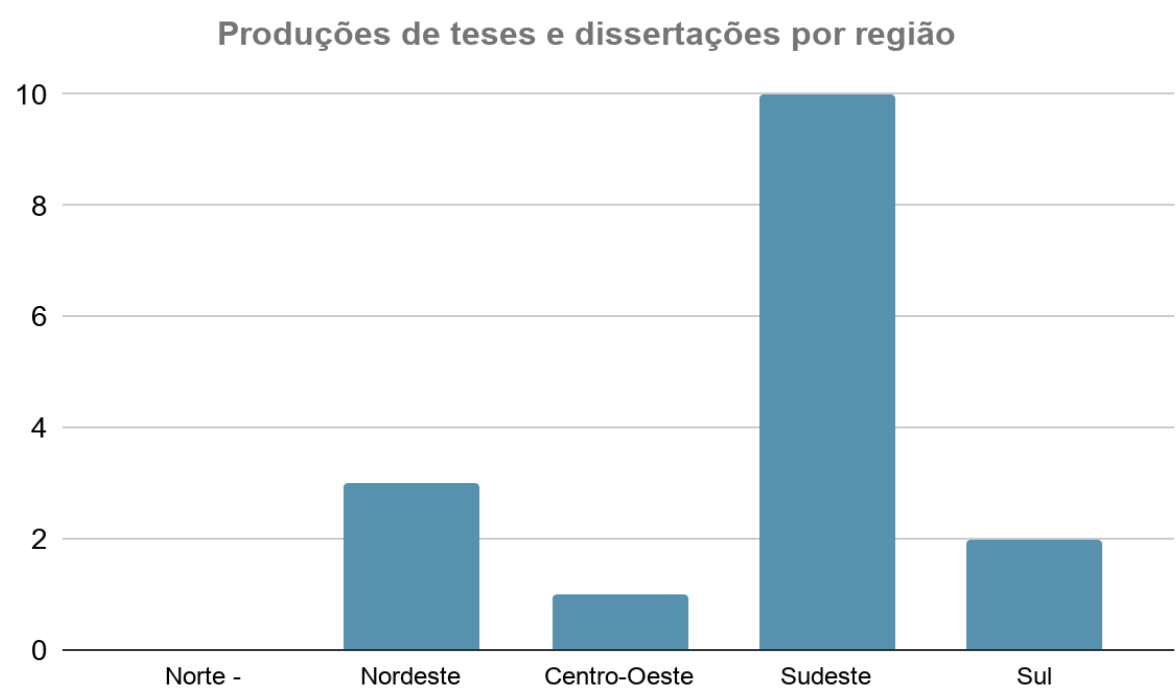

Fonte: Dados da pesquisa (2021). 
Como mostra a Figura 1, a região que mais produziu trabalhos nesse período foi a Sudeste, com $10(62,5 \%)$ trabalhos, com destaque para a Universidade Federal de São Carlos e a Universidade de São Paulo, com 3 (18,75\%) produções cada. As outras instituições que surgiram nos resultados foram a Universidade Estadual Paulista (Unesp), campus Marília e Rio Claro; a Universidade Federal do Espírito Santo e a Pontifícia Universidade Católica de São Paulo, com 1 (6,25\%) produção cada. Esses dados condizem com a revisão de Maturana e Cia (2015), na qual o Sudeste também aparece como a região brasileira com maior número de produções sobre educação especial e a relação família-escola.

A região Nordeste segue com 3 (18,8\%) produções, referentes às Universidade Federal do Rio Grande do Norte; Universidade Federal do Ceará e Universidade Federal do Maranhão. A região Sul apareceu com 2 (12,5\%) produções das Universidade Regional de Blumenau e Universidade Católica de Pelotas. A região Centro-Oeste teve apenas 1 (6,3\%) publicação advinda da Universidade Federal da Grande Dourados. Na região Norte não teve nenhuma produção.

Quanto aos programas de pós-graduação, os programas de Educação se destacaram com 9 (56,3\%) trabalhos produzidos, os programas de Educação Especial contabilizaram 3 (18,8\%), os de Psicologia $2(12,5 \%)$ e os de Educação Matemática e Política Social contabilizaram $1(6,3 \%)$ trabalho cada.

Sobre a metodologia de pesquisa, $5(31,25 \%)$ pesquisas não deixaram claro qual foi o método adotado no resumo ou mesmo no capítulo sobre os aspectos metodológicos, o que também foi visto em Maturana e Cia (2015) e Lima e Machado (2018), que fizeram estados da arte sobre a relação família-escola nas pesquisas de pós-graduação brasileiras. Assim, precisou-se fazer uma leitura crítica dos trabalhos para compreender esse aspecto.

Houve $6(37,5 \%)$ trabalhos que utilizaram mais de um método de pesquisa. As seguintes metodologias foram utilizadas: descritiva (8 - 50\%); estudo de caso (4 - 25\%); documental (3 18,8\%); pesquisa de campo (2 - 12,5\%); história oral (2 - 12,5\%); etnografia; pesquisa participante; ex-post-facto e investigação social empírica e grupo focal, com 1 (6,3\%) pesquisa cada.

A pesquisa descritiva também apareceu como a mais utilizada na análise de Maturana e Cia (2015), no estado da arte de Lima e Machado (2018) e na análise de Manzini et al. (2006), que objetivaram analisar as teses e as dissertações sobre a educação especial produzidas no programa de pós-graduação em educação da Unesp - Marília, de 1993 a 2004. Isso confirma ser a pesquisa descritiva muito utilizada no campo da educação, da educação especial e das pesquisas sobre a relação família-escola. Tal fato corrobora com Maturana e Cia (2015) quanto à necessidade de mais pesquisas que intervenham na realidade pesquisada e não apenas a descreva. 
Sobre os sujeitos participantes das pesquisas, mesmo que se tenha objetivado levantar apenas trabalhos que consideram a perspectiva de familiares, os trabalhos apresentam diferentes configurações de sujeitos, como mostra a Tabela 1:

Tabela 1 - Configuração de participantes das pesquisas

\begin{tabular}{|c|c|}
\hline Configuração & Quant. (\%) \\
\hline Familiares ou responsáveis & $8(50 \%)$ \\
\hline $\begin{array}{c}\text { Familiares ou responsáveis e profissionais da } \\
\text { escola (professores, gestores, entre outros) }\end{array}$ & $2(12,5 \%)$ \\
\hline Familiares ou responsáveis e alunos (as) & $3(18,8 \%)$ \\
\hline $\begin{array}{c}\text { Familiares ou responsáveis, alunos (as) e pro- } \\
\text { fissionais da escola }\end{array}$ & $3(18,8 \%)$ \\
\hline
\end{tabular}

Fonte: Dados da pesquisa (2021).

Pesquisas apenas com familiares ou responsáveis apareceram em metade dos trabalhos encontrados, sendo a configuração mais comum. Um aspecto a se destacar é que em $5(31,25 \%)$ das pesquisas aparece algum outro responsável, que não é o pai ou a mãe. Apresentou-se ser comum tias, avós e até irmãos ou irmãs responderem como responsáveis pela pessoa com deficiência. Isso aponta para a diversidade da configuração de famílias no Brasil, que ultrapassa o núcleo pai, mãe e filhos.

Já desde a segunda metade do século XX, os estudos apontam a variação de sua organização para além desse núcleo fechado, englobando as redes familiares e sociais dentro do universo familiar. Alguns elementos fundamentais para a formação dessas redes é que elas são construídas pelos vínculos de consanguinidade, aliança, afinidade, assim como também de relações de subordinação e/ou dependência (SCOTT, 2009).

Sobre o gênero dos participantes dos trabalhos, em $6(37,5 \%)$ pesquisas apenas as mães aparecem como familiar responsável e em outros 5 (31,25\%) trabalhos, a maioria dos familiares responsáveis são mães, tias ou avós. Em outras palavras, em 11 (68,75\%) pesquisas, apenas mães ou responsáveis mulheres aparecem como participantes. A maioria dos trabalhos aponta que os participantes escolhidos foram aqueles que são responsáveis pela escolarização da pessoa com deficiência, o que indica que as mulheres continuam como aquelas incumbidas dos cuidados de filhos e familiares. 
Marques (2019) nos aponta que, na nossa sociedade, as relações de gênero construídas socialmente, articuladas às normativas sociais, símbolos culturais e condições socioeconômicas resultam em relações desiguais. Essas desigualdades se expressam na manutenção de concepções do que é ser mulher, impondo-lhe a responsabilidade quase exclusiva do ato de cuidar. Tais desigualdades ficam visíveis nas pesquisas.

Tabela 2 - Público-alvo das pesquisas

\begin{tabular}{|c|c|}
\hline Deficiência & Quant. (\%) \\
\hline Deficiências (não especificado) & $4(25 \%)$ \\
\hline Deficiência Intelectual & $7(43,8 \%)$ \\
\hline Cegueira e/ou Baixa Visão & $2(12,5 \%)$ \\
\hline Transtorno Global do Desenvolvimento & $2(12,5 \%)$ \\
\hline Síndrome de Down & $1(6,3 \%)$ \\
\hline Deficiência Física & $1(6,3 \%)$ \\
\hline Microcefalia & $1(6,3 \%)$ \\
\hline Paralisia Cerebral & $1(6,3 \%)$ \\
\hline Altas Habilidades/Superdotação & $1(6,3 \%)$ \\
\hline
\end{tabular}

Fonte: Dados da pesquisa (2021).

A Tabela 2 aponta sobre o público-alvo dos trabalhos encontrados, em que a deficiência intelectual aparece em sete (GÓES, 2012; PINTO, 2013; FREITAS, 2014; MENDONÇA, 2014; SOUZA, 2016; SANTOS, 2017; MONTEIRO, 2019), sendo a mais pesquisada. Encontrou-se quatro trabalhos que tinham como público-alvo pessoas com deficiências não especificadas (TINÓS, 2010; COSTA, 2011; BASTOS, 2012; GUALDA, 2015). Duas pesquisas destinaram-se a investigar sobre a cegueira e/ou baixa visão (BAZON, 2009; ROSA, 2017) e duas sobre transtorno global do desenvolvimento (GÓES, 2012; CRUZ, 2013). A síndrome de down (CRUZ, 2013), deficiência física (GREGORUTTI, 2017), microcefalia (CRUZ, 2013), paralisia cerebral (CONCEIÇÃO, 2014) e altas habilidades/superdotação tiveram apenas uma pesquisa cada.

Decidiu-se incluir pesquisas que tinham como público-alvo crianças com transtornos globais do desenvolvimento e altas habilidades/superdotação, pois elas são do público-alvo da educação especial e estão sujeitas às dificuldades variadas no processo de inclusão escolar. 
Tabela 3 - Temas principais abordados nas pesquisas

\begin{tabular}{|c|c|}
\hline Tema & Quant. (\%) \\
\hline Trajetória Escolar & $6(37,5 \%)$ \\
\hline Participação/Inclusão Escolar & $3(18,75 \%)$ \\
\hline Relação Família-Escola & $3(18,75 \%)$ \\
\hline Ensino/Aprendizagem & $2(13,5 \%)$ \\
\hline Políticas em Educação Especial & $2(13,5 \%)$ \\
\hline
\end{tabular}

Fonte: Dados da pesquisa (2021)

A Tabela 3 aponta os temas principais que foram abordados nas pesquisas encontradas. O tema da trajetória escolar foi o mais retratado, representando 6 (37,5\%) trabalhos. Definiu-se, nessa categoria, as pesquisas que buscaram compreender e analisar o percurso escolar traçado pelos alunos que já passaram por pelo menos mais de uma experiência escolar, seja ela de discentes que estão nos anos iniciais ou daqueles que já saíram da escola regular e têm mais experiências para serem analisadas.

Tinós (2010) teve como objetivo reconhecer e desvelar as trajetórias escolares de alunas com deficiência e os seus principais resultados apontaram que os serviços educacionais vivenciados pelas alunas não apresentaram a qualidade prevista na legislação, assim, elas precisaram dispor de um grande esforço unilateral para acessá-los, mostrando a distância entre os direitos garantidos pela legislação e a realidade vivenciada por elas.

Costa (2011) investigou o percurso escolar de alunos com deficiência matriculados na quinta série. Os familiares foram ouvidos apenas sobre os aspectos sociais, econômicos e culturais da família; e alunos, com o objetivo de caracterizá-los. A autora concluiu que a deficiência foi a marca principal na trajetória escolar dos discentes, principalmente quando confrontada com a realidade das escolas, que apresentavam condições insatisfatórias para atender à diversidade dos estudantes.

Góes (2012) investigou os motivos que levaram pais de crianças com autismo e deficiência intelectual associada a matricularem os seus filhos na educação infantil em escolas de educação especial. A trajetória de escolarização dessas crianças mostrou que os pais procuraram a escola regular, mas pelas inúmeras dificuldades encontradas e por uma postura de não enfrentamento dessas dificuldades, decidiram adaptar-se e optaram pela instituição privada e especial.

Freitas (2014), que teve como objetivo compreender o processo de escolarização de jovens com deficiência intelectual que frequentam a Educação de Jovens e Adultos (EJA), aponta que os 
alunos com deficiência intelectual dessa modalidade de ensino carregam um histórico de muitas mudanças escolares e longas permanências no ensino fundamental, em escolas e classes especiais, assim como na própria EJA, o que também foi visto na pesquisa de Tinós (2010). A defasagem idade-série é apresentada como um fator que dificulta a inclusão na escola regular. Para a família, a modalidade EJA era o único espaço que dispunham para o atendimento dos jovens.

Rosa (2017) buscou compreender como os alunos com deficiência visual e os seus responsáveis percebem o processo de escolarização, a partir da perspectiva da educação matemática. A autora também refletiu sobre como a família e os alunos construíram sua trajetória escolar, as dificuldades encontradas, a construção da identidade pessoal da pessoa com deficiência e as mudanças necessárias na sociedade para que a inclusão ocorra.

Por fim, Santos (2017) analisou como as experiências escolares de jovens com deficiência intelectual interferem na formação das suas identidades. Apesar de ter como foco a perspectiva da pessoa com deficiência intelectual, tias e mães também foram ouvidas. $\mathrm{O}$ autor verificou que a escolarização de pessoas com deficiência intelectual em salas regulares é marcada pela precarização dos processos de inclusão, reforçando o estigma de que a pessoa com deficiência intelectual não aprende ou se desenvolve e que a escola regular não é o lugar delas. O autor ainda aponta a necessidade de se criar ambientes escolares menos restritivos e que possibilitem a construção de identidades que não sejam marcadas por limitações, mas pela multiplicidade de atributos e potenciais.

As pesquisas que abordaram as trajetórias escolares dos alunos com deficiência destacaram que elas são marcadas por dificuldades na inclusão da pessoa com deficiência na escola regular, principalmente dos alunos com deficiência intelectual ou autismo e deficiência intelectual associada, já que representaram juntos mais da metade das pesquisas encontradas. Os trabalhos apontaram que o estigma ainda associado à deficiência intelectual é um fator que atrasa o desenvolvimento de práticas mais inclusivas. Além disso, a EJA parece ser uma escolha comum para jovens e adultos com deficiência intelectual após uma trajetória escolar difícil, seja em escolas regulares e/ou especiais.

No levantamento, $3(18,75 \%)$ pesquisas tinham como temática principal a participação ou a inclusão escolar dos alunos. Nessa categoria foram classificadas as pesquisas que buscavam entender como ocorre a participação do aluno dentro da escola e se as práticas dos profissionais da escola eram inclusivas ou não. Esta categoria se difere daquela que buscou entender a trajetória escolar, pois os trabalhos não tinham como foco analisar várias experiências escolares, mas apenas a experiência do aluno no momento que a pesquisa foi realizada.

Cruz (2013) buscou entender como a família da criança com deficiência, transtornos globais do desenvolvimento e altas habilidades/superdotação percebe o processo de inclusão dos seus 
filhos no contexto das salas comuns da educação infantil. Os resultados indicaram a dificuldade da família em aceitar a deficiência e a vivência de sentimentos de insegurança quanto ao futuro das crianças, mas definem a experiência escolar como positiva, mesmo com desconhecimento sobre as políticas e os direitos de seus filhos.

Pinto (2013) estudou sobre a inclusão escolar de adolescentes com deficiência intelectual na rede pública de ensino a partir da percepção dos pais. A autora indicou que mesmo com os pais presentes na vida escolar dos seus filhos, eles desconheciam como ocorre a inclusão no contexto escolar e demonstravam insatisfação com a falta de atenção às necessidades educacionais. Os pais ainda apontaram dificuldades de comunicação e ausência de diálogo por parte dos profissionais da escola. Além disso, a falta de conhecimento da equipe escolar sobre a deficiência intelectual contribuiu para perpetuar estigmas sobre a deficiência.

Monteiro (2019) investigou a participação de crianças com deficiência intelectual no processo de escolarização, articulando-a com a legislação e as políticas públicas de inclusão. A autora concluiu que a inclusão escolar está garantida do ponto de vista legal e é apoiada pela comunidade escolar, mas existem desafios e barreiras pedagógicas e atitudinais que a comprometem. Os pais e os professores apontaram a necessidade de capacitação deles e a presença de um auxiliar de ensino de educação especial em sala de aula como essenciais para a mediação do processo ensino/aprendizagem dos estudantes com deficiência intelectual.

A categoria relação família-escola apareceu em 3 (18,75\%) trabalhos. Elencou-se, nessa categoria, os trabalhos que abordavam especificamente como ocorre a relação, a comunicação e a cooperação entre os familiares dos alunos com deficiência e os profissionais da escola, além de como essas relações contribuem para a inclusão escolar.

Bazon (2009) buscou identificar como a inclusão escolar da criança com deficiência visual influencia na sua relação familiar e como também reflete no processo de inclusão dessas crianças. A autora teve como conclusões que atitudes cooperativas da família com a escola, assim como a atitude de abertura e a disponibilidade da instituição favoreciam a inclusão e o desenvolvimento dos alunos. A inserção do aluno com deficiência visual na escola alterou a dinâmica familiar e construiu novas perspectivas e expectativas sobre o desenvolvimento da criança. Atitudes de preconceito, barreiras atitudinais e falta de formação dos professores afetaram de forma negativa o processo de inclusão.

Gualda (2015) tratou sobre a relação família-escola na opinião de pais e responsáveis de pré-escolares com deficiência matriculados em instituições de ensino comuns e outras especializadas. A autora apontou que as famílias que possuíam filhos matriculados em escolas comuns ou em 
escolas comuns e instituições especializadas, mutuamente, iam à escola com mais frequência do que aqueles matriculados apenas em instituições especializadas.

As famílias nas quais os filhos estudavam apenas na escola comum, também conversavam com maior frequência com os professores sobre assuntos diferenciados, quando comparadas com as famílias que tinham filhos matriculados em instituições especializadas ou que frequentavam ambas. A autora também trouxe conclusões relacionadas ao suporte social recebido pelas famílias e aos recursos familiares, ambientes familiares estimuladores e interativos.

Souza (2016) buscou identificar e descrever as opiniões de familiares sobre a relação entre profissionais da escola e a família do aluno com deficiência intelectual. A autora apontou a utilização de estratégias de comunicação entre a família e os profissionais, assim como comportamentos dos profissionais da escola que contribuíram para a ocorrência e a manutenção da comunicação. As famílias relataram queixas e elogios aos profissionais, o que permitiu indicar progressos e estimular potencialidades dessa relação.

Elencou-se na categoria ensino/aprendizagem 2 (13,5\%) trabalhos que abordaram aspectos específicos das práticas de ensino da escola e os processos de aprendizagem dos alunos. No trabalho de Mendonça (2014), os objetivos que tiveram como foco a perspectiva da família, buscaram conhecer as dificuldades relacionadas à avaliação da aprendizagem dos alunos com deficiência intelectual pelas falas dos professores, alunos e seus familiares ou responsáveis, além de coletar sugestões para melhorias educacionais e construção de novas práticas avaliativas.

Nos resultados de Mendonça (2014), os familiares e os responsáveis demonstraram indiferença quanto a como ocorre a avaliação dos filhos, alguns encontraram dificuldades ou percebiam que o aluno era excluído da avaliação que o restante da classe fazia. A partir das sugestões dos professores e familiares ou responsáveis, a autora conclui que é necessário um esforço coletivo para assegurar a qualidade da educação inclusiva e que as mudanças configurem-se no processo de ensino e aprendizagem, para que o estudante com deficiência intelectual não apenas se socialize, mas que a escola seja um espaço favorável à evolução das capacidades de todos os aprendizes.

Gregorutti (2017) investigou o envolvimento de pais e familiares responsáveis por alunos com deficiência física na realização da tarefa de casa. Os resultados apontaram o bom acolhimento da tarefa de casa por parte dos familiares, entretanto, demonstrou-se a necessidade de uma comunicação mais efetiva entre a professora e os familiares cuidadores, para que pudessem auxiliar mais adequadamente na realização das atividades e para que a professora soubesse das dificuldades encontradas em realizá-las. 
Assim, Gregorutti (2017) aponta que o envolvimento dos familiares na realização da tarefa de casa pode ser uma estratégia importante para promover um bom desempenho acadêmico do aluno com deficiência física e para criar condições de colaboração entre a família e a escola.

$\mathrm{Na}$ categoria políticas em educação especial também foram elencados $2(13,5 \%)$ trabalhos. Nessa categoria, encontram-se as pesquisas que tinham como foco principal discutir as políticas educacionais e como elas foram vivenciadas na realidade escolar das crianças com deficiência.

Bastos (2012) verificou como a implantação da política de educação especial na perspectiva da educação inclusiva foi percebida pelos pais e responsáveis de alunos com deficiência matriculados na rede regular municipal de Pelotas (RS). A pesquisa apontou que, de modo geral, os pais e os responsáveis acreditam que as escolas onde os seus filhos estão matriculados são acessíveis, apesar de apontarem dificuldades na acessibilidade do transporte escolar e dificuldades linguísticas. Ainda assim, a política foi vista como uma conquista importante e um avanço na garantia dos direitos à educação dos seus filhos.

Conceição (2014) pretendeu, no seu estudo, apresentar fatos e marcos legais que o permitiram mapear o surgimento da educação inclusiva. O autor também realizou um estudo de caso com uma criança com paralisia cerebral. Nos seus resultados, ele entrelaça os discursos dos profissionais e familiares com as políticas públicas às quais a criança tem acesso, garantindo que elas ganhem concretude e ressignificação nas relações estabelecidas entre a criança, familiares e profissionais da educação.

Percebe-se nas pesquisas que há intenção, por parte dos familiares e profissionais da educação, de concretizar as políticas de educação especial numa perspectiva da educação inclusiva na realidade dos alunos investigados. Mesmo com as dificuldades que a realidade impõe, as famílias veem as políticas de uma forma positiva e que contribuem para a garantia dos direitos das pessoas com deficiência.

Sobre a concepção de deficiência, o modelo social foi o mais utilizado, estando presente em $13(81,3 \%)$ trabalhos, de forma explícita ou implícita. Considerou-se que o trabalho adotou essa concepção quando levou em consideração não apenas a deficiência do aluno e as suas características biológicas, mas também o contexto social e as barreiras que são impostas às pessoas com deficiência. Da mesma forma, analisou-se que $3(18,8 \%)$ trabalhos adotaram uma concepção médico patológica de deficiência, por dar muita atenção aos aspectos biologizantes, atribuindo à pessoa com deficiência uma responsabilidade unilateral sobre a sua inclusão.

Ao assumir a família e a escola como instituições que podem ou não favorecer a inclusão escolar da pessoa com deficiência, pressupõe-se, em parte, a adoção do modelo social da deficiência, em que a sociedade e as suas instituições devem se transformar para que a inclusão seja efetiva. 
Nessa concepção, a pessoa com deficiência é vista não apenas como alguém com dificuldades e déficits, mas também como alguém com potencialidades que podem ser valorizadas no processo de inclusão escolar e, para isso, torna-se necessário rever as práticas educativas e aperfeiçoá-las.

Concordamos com Magalhães (2002, p. 22) que auxiliar na construção de um novo olhar sobre a pessoa com deficiência é o ponto principal para a construção de uma escola e de uma sociedade que abrace a diferença e a diversidade e que "cumpra a sua função de capacitar pessoas para o exercício da liberdade e da autonomia”. Assim, entender a perspectiva da família, que é uma das instituições mais imbricadas nesse processo, pode trazer grandes contribuições sobre as dificuldades e as potencialidades que precisam ser contempladas no processo educativo.

\section{Considerações Finais}

Acredita-se que analisar as produções acadêmicas sobre a inclusão escolar de pessoas com deficiência que consideravam a perspectiva das famílias trouxe muitas contribuições para entender como a temática vem sendo estudada e criar um panorama desses estudos. Percebe-se que a maioria das pesquisas estão concentradas na região sudeste do país e, de uma forma geral, em programas de pós-graduação em educação. Porém, o programa de pós-graduação em educação especial da Universidade Federal de São Carlos foi o que mais concentrou trabalhos nesta temática.

A grande maioria das pesquisas foi realizada em dissertações de mestrado acadêmico, sendo poucas as teses de doutorado que abordaram a temática. Sobre as plataformas de dados utilizadas, apesar da Biblioteca Digital Brasileira de Teses e Dissertações ter sido a base de dados que mais apresentou resultados, o Catálogo de Teses e Dissertações da Capes foi mais preciso quanto aos resultados da busca.

Encontrou-se dificuldades quanto aos aspectos metodológicos de algumas pesquisas, pois essas não eram claras quanto à metodologia utilizada ou mesmo quanto à coerência entre os seus objetivos iniciais e os resultados apresentados. A maioria das pesquisas eram descritivas, dessa forma, corrobora-se com Maturana e Cia (2015) quanto à necessidade de mais trabalhos que possam intervir na realidade pesquisada e não apenas descrevê-la.

Quanto aos participantes das pesquisas, apesar dos pais e responsáveis terem sido a maioria, houve diversificação dos sujeitos entrevistados, com destaque para as pesquisas que buscaram a perspectiva de todos os sujeitos imbricados no processo de inclusão escolar, como alunos, familiares, professores e profissionais da escola. Esses estudos trouxeram contribuições importantes a serem acatadas no processo de escolarização, como, por exemplo, a necessidade de colaboração e comunicação entre família e escola. 
A deficiência intelectual foi a mais pesquisada nos trabalhos. Destacam-se as pesquisas que consideraram a vOz dos próprios alunos com deficiência, além dos seus familiares e professores. Também pode-se perceber pelos resultados que as pessoas com deficiência intelectual enfrentam barreiras significativas nos seus processos de inclusão na escola regular, o que, muitas vezes, os faz buscar escolas e classes especiais. Nesse sentido, são necessárias mais pesquisas que possam apontar soluções para essa problemática.

A trajetória escolar foi a temática mais pesquisada e as narrativas construídas pelas pessoas com deficiência e suas famílias contribuem para a percepção do que ainda precisa ser mudado no contexto da escola regular. A maioria dos alunos investigados nessa categoria possuem deficiência intelectual e se pode constatar que o estigma relacionado a ela ainda é forte no imaginário social. Barreiras atitudinais e a crença de que a pessoa com deficiência intelectual não aprende e se desenvolve ainda têm sido responsáveis pela exclusão dessas pessoas na escola regular.

Destaca-se, ainda, que a maioria das pesquisas apresentaram como pressuposto o modelo social da deficiência, o que mostra o grande avanço que os pesquisadores e as políticas de educação especial numa perspectiva inclusiva conquistaram. Entretanto, as práticas educativas investigadas nas pesquisas ainda não condizem com a concepção em que os sistemas e a sociedade adaptam-se para incluir a pessoa com deficiência. Faz-se necessário uma maior capacitação dos profissionais da educação para lidarem com a diferença presente na sala de aula e ultrapassarem os estigmas que ainda persistem em atrapalhar as suas práticas.

Conclui-se que considerar os diversos aspectos que estão envoltos no processo de inclusão escolar da pessoa com deficiência permite contemplar caminhos em que a diversidade de sujeitos e de corpos é valorizada. Aponta-se a necessidade de trabalhos sobre a inclusão escolar e a perspectiva da família que contemplem uma maior diversidade de deficiências para compreender-se as dificuldades e potencialidades encontradas pela relação família e escola.

\section{Referências}

BARDIN, Laurence. Análise de conteúdo. São Paulo: Edições 70, 2011. 229 p.

BASTOS, Flúvia Ribeiro. Politica de educação inclusiva em pelotas: percepções e interpretações dos responsáveis pelos alunos com deficiência incluídos nas escolas regulares municipais. Orientadora: Vini Rabassa da Silva. 2012. 159 f. Dissertação (Mestrado em Política Social) - Universidade Católica de Pelotas, Pelotas, 2012.

BAZON, Fernanda Vilhena Mafra. As mútuas influências, família-escola, na inclusão escolar de crianças com deficiência visual. Orientadora: Elcie Apparecida Fortes Salzano Masini . 2009. 574 f. Tese (Doutorado em Educação) - Universidade de São Paulo, São Paulo, 2009. 
BRASIL. Convenção sobre os direitos das pessoas com deficiência: protocolo facultativo à convenção sobre os direitos das pessoas com deficiência. Brasília, DF: 2007.

BRASIL. Constituição (1988). Constituição da República Federativa do Brasil. Brasília, DF: Senado Federal: Centro Gráfico, 1988.

BRASIL. Decreto $n^{\circ}$ 6.949, de 25 de agosto de 2009. Promulga a convenção internacional sobre os direitos das pessoas com deficiência e seu protocolo facultativo, assinados em Nova York, em 30 de março de 2007. 2009.

BRASIL. Lei 7.853, de 24 de outubro de 1989. Brasília, DF: 1989.

BRASIL. Lei Brasileira de Inclusão da Pessoa com Deficiência. Lei no 13.146 de 2015. Brasília, DF: 2015.

BRASIL. Lei de Diretrizes e Bases da Educação Nacional. Lei no 9.394 de 20 de dezembro de 1996. Brasília, DF: 1996.

BRASIL. MEC. Política nacional de educaşão especial na perspectiva da educação inclusiva. Documento elaborado pelo Grupo de Trabalho nomeado pela Portaria no 555/2007, prorrogada pela Portaria $n^{\circ}$ 948/2007, entregue ao Ministro da Educação em 07 de janeiro de 2008. Brasília: 2008.

CONCEIÇÃO, Luiz Henrique de Paula. Educação para todos: a construção de cultura, políticas e práticas inclusivas a partir de um estudo de caso sobre uma estudante com deficiência na escola comum. Orientador: Lineu Norió Kohatsu. 2014. 151 f. Dissertação (Mestrado em Psicologia) Universidade de São Paulo, São Paulo, 2014.

COSTA, Maria Elizabete da. Alunos com deficiência e condições escolares, sociais e culturais: um estudo na rede pública estadual de São Paulo. Orientador: Carlos Antonio Giovinazzo Júnior. 2011. 117 f. Dissertação (Mestrado em Educação: história, política, sociedade) - Pontifícia Universidade Católica de São Paulo, São Paulo, 2011.

CRUZ, Daniella Messa e Melo. O que a família de crianças com deficiência tem a nos dizer sobre a inclusão escolar de seus filhos? Orientador: Rogério Drago. 2013. 151 f. Dissertação (Mestrado em Educação) - Universidade Federal do Espírito Santo, Vitória, 2013.

DESSEN, Maria Auxiliadora; POLONIA, Ana da Costa. A família e a escola como contextos de desenvolvimento humano. Paidéia, Ribeirão Preto, v. 17, n. 36, p. 21-32, Jan/Abr 2007.

DINIZ, Debora; BARBOSA, Lívia; DOS SANTOS, Wederson Rufino. Deficiência, direitos humanos e justiça. Sur. Revista Internacional de Direitos Humanos, São Paulo, v. 6, n. 11, p. 61-71, Dez/2009.

FREITAS, Mariele Angélica de Souza. Estudantes com deficiência intelectual na educação de jovens e adultos: interfaces do processo de escolarização. Orientadora: Juliane Ap. de Paula Perez Campos. 2014. 140 f. Dissertação (Mestrado em Educação Especial) - Universidade Federal de São Carlos, São Carlos, 2014.

GIL, Antonio Carlos. Métodos e técnicas de pesquisa social. 6. ed. São Paulo: Atlas, 2008.

GODOY, H. P. Inclusão de alunos portadores de deficiência no ensino regular paulista: recomendações internacionais e normas oficiais. São Paulo: Mackenzie, 2002. 
GÓES, Ricardo Schers. A escola de educação especial: uma escolha para crianças autistas e com deficiência intelectual associada de 0 a 5 anos. Orientadora: Marie Claire Sekkel. 2012. 99 f. Dissertação (Mestrado em Psicologia) - Universidade de São Paulo, São Paulo, 2012.

GREGORUTTI, Carolina Cangemi. A tarefa de casa e o envolvimento familiar na inclusão escolar de alunos com deficiência física. Orientador: Sadao Omote. 2017. 191 f. Tese (Doutorado em Educação) Universidade Estadual Paulista "Júlio de Mesquita Filho", Marília, 2017.

GUALDA, Danielli Silva. Variáveis familiares de crianças com deficiência e os tipos de escolarização inclusiva e segregada. Orientadora: Fabiana Cia. 2015. 161 f. Dissertação (Mestrado em Educação Especial) Universidade Federal de São Carlos, São Carlos, 2015.

LIMA, Andreza Maria; MACHADO, Laêda Bezerra. Relação família-escola: o estado da arte na pós-graduação brasileira. EccoS-Revista Científica, São Paulo, n. 46, p. 149-169, maio/ago 2018.

MAGALHÃES, Rita de Cássia Barbosa Paiva. Traduções para as palavras diferença/deficiência: um convite à descoberta. In: MAGALHÃES, Rita de Cássia Barbosa Paiva. Reflexões sobre a diferença: uma introdução à educação especial. Fortaleza: Edições Demócrito Rocha, 2002. 228 p.

MANZINI, Eduardo José; PAULINO, Vanessa Cristina; CORRÊA, Priscila Moreira; DA SILVA, Michele Oliveira; LOPES, Mara Aparecida de Castilho. Análise de dissertações e teses em educação especial produzidas no Programa de Pós-Graduação em Educação da UNESP-Marília (1993-2004). Revista Educação Especial, Santa Maria, n. 28, 2006.

MARQUES, Maria de Fátima Jeronimo. Questões de gênero na vida de mulheres mães de crianças com deficiência. Orientadora: Rita de Cássia Barbosa Paiva Magalhães. 2019. 220 f. Tese (Doutorado em Educação) - Universidade Federal do Rio Grande do Norte, Natal, 2019.

MATURANA, Ana Paula Pacheco Moraes; CIA, Fabiana. Educação Especial e a Relação Família-Escola: análise da produção científica de teses e dissertações. Revista Quadrimestral da Associação Brasileira de Psicologia Escolar e Educacional, São Paulo, v. 19, n. 2, p. 349-358, Maio/Agosto de 2015.

MENDONÇA, Andréia Vieira de. Desenvolver potenciais e valorar capacidades: avaliação da aprendizagem de alunos com deficiência intelectual em escolas municipais de Fortaleza - CE. Orientadora: Tania Vicente Viana. 2014. 144 f. Dissertação (Mestrado em Educação) - Universidade Federal do Ceará, Fortaleza, 2014.

MONTEIRO, Janete Lopes. A participação de alunos com deficiência intelectual no seu processo de escolarização - estudo em uma escola da rede municipal de Florianópolis (SC). Orientadora: Rita de Cássia Marchi. 2019. 156 f. Dissertação (Mestrado em Educação) - Universidade Regional de Blumenau, Blumenau, 2019.

PINTO, Maisa Cunha. Inclusão escolar do adolescente com deficiência intelectual na rede pública de ensino: percepção dos pais. Orientadora: Marilete Geralda da Silva . 2013. 153 f. Dissertação (Mestrado em Educação) - Universidade Federal do Maranhão, São Luís, 2013.

POLONIA, Ana da Costa; DESSEN, Maria Auxiliadora. Em busca de uma compreensão das relações entre família e escola. Psicologia escolar e educacional, São Paulo, v. 9, n. 2, p. 303-312, 2005.

ROSA, Fernanda Malinosky Coelho da. Histórias de vida de alunos com deficiência visual e de suas mães: um estudo em educação matemática inclusiva. Orientadora: Ivete Maria Baraldi. 2017. 260 f. Tese 
(Doutorado em Educação Matemática) - Universidade Estadual Paulista "Júlio de Mesquita Filho", Rio Claro, 2017.

SANTOS, Rogério Alves dos. A voz dos estudantes com deficiência intelectual: rebatimentos dos tempos de escola na construção identitária. Orientadora: Rita de Cássia Barbosa Paiva Magalhães. 2017. 197 f. Dissertação (Mestrado em Educação) - Universidade Federal do Rio Grande do Norte, Natal, 2017.

SASSAKI, Romeu Kazumi. Inclusão: construindo uma sociedade para todos. Rio de Janeiro: WVA, 2006.

SCOTT, Ana Silvia Volpi. As teias que a família tece: uma reflexão sobre o percurso da história da família no Brasil. História: Questões e Debates, Curitiba, n. 51, p. 13-29, jul/dez 2009.

SMITH, Deborah Deutsch. O contexto da educação especial: um tempo de oportunidade. In: SMITH, Deborah Deutsch. Introdução à educação especial: ensinar em tempos de inclusão. Trad. Sandra Moreira de Carvalho. 5. ed. Porto Alegre: Artmed, 2008. p. 27-51.

SOUZA, Annye de Picoli. Relação escola e família de alunos com deficiência intelectual: o ponto de vista dos familiares. Orientadora: Aline Maira da Silva. 2016. 100 f. Dissertação (Mestrado em Educação) Universidade Federal da Grande Dourados, Dourados, 2016.

TINÓS, Lúcia Maria Santos. Caminhos de alunos com deficiência à educação de jovens e adultos: conbecendo e compreendendo trajetórias escolares. Orientadora: Fátima Elisabeth Denari. 2010. 137 f. Tese (Doutorado em Educação Especial) - Universidade Federal de São Carlos, São Carlos, 2010.

UNESCO. Declaração de Salamanca: Sobre Princípios, Políticas e Práticas na Área das Necessidades Educativas Especiais. 1994. Disponível em: http://portal.mec.gov.br/seesp/arquivos/pdf/salamanca.pdf. Acesso em: 20 maio 2021.

UNICEF. Convenção sobre os direitos da criança. 1989. Disponível em: https:/ /www.unicef.org/bra$\mathrm{zil/convencao-sobre-os-direitos-da-crianca.} \mathrm{Acesso} \mathrm{em:} 20$ maio 2021.

UNICEF. Declaraşão mundial sobre a educação para todos. 1990. Disponível em: https://www.unicef.org/brazil/declaracao-mundial-sobre-educacao-para-todos-conferencia-de-jomtien-1990. Acesso em: 20 maio 2021. 